\title{
The Survival of Bacteria under Starvation Conditions: a Mathematical Expression of Microbial Death
}

\author{
By KAORU KUMADA, * KAZUKO KOIKE AND KIKUO FUJIWARA \\ Institute of Community Medicine, Tsukuba University, Ibaraki, Japan
}

(Received 3 January 1985; revised 12 March 1985)

\begin{abstract}
Microbial death was studied under starvation conditions. The kinetics of cell death were described by $\mathrm{d} N / \mathrm{d} t=\kappa N^{\alpha+1}$, where $N$ is the number of viable cells at time $t$, and $\kappa$ and $\alpha$ are constants concerning growth or death of bacteria. Death in the decline phase of the culture also fitted the above equation, except for irregular oscillations with relatively short periods. This suggested that bacterial death in the decline phase was mainly caused by the same factor(s) as death under starvation conditions.
\end{abstract}

\section{INTRODUCTION}

Most textbooks of microbiology state that the kinetics of death of bacterial populations is exponential (Stanier et al., 1976; Salle, 1973; Rahn, 1945), but other authors present several examples of non-exponential survival curves (Yanagita, 1981; Wilson \& Miles, 1946; Moats, 1971). Fluctuations in the number of viable cells in the decline phase were suggested to result from a sudden growth of mutants resistant to the adverse conditions, at the expense of nutrient released from lysed cells. The reason for the gradual decrease of death rate of the population was the same (Yanagita, 1981). Rahn (1930) pointed out the non-exponential death of bacteria: the death rate decreased and the survival curve lagged below the expected straight line in semilogarithmic plots. However, Rahn (1945) rejected this view. Moats (1971) proposed a mathematical method of calculating the kinetics of thermal death of bacteria which was based on the 'multiple-target theory'. Peled et al. (1977) presented an improved theory and applied it to describe the kinetics of death of starved yeast cells.

In the present study the death of bacteria under starvation conditions, and in the decline phase in batch culture, was investigated; an equation is proposed which fits the experimental data.

\section{METHODS}

Bacterial strains. Escherichia coli IFM 3293, Serratia marcescens IFM 3248, Salmonella typhimurium, Proteus morganii IFM 3201 and Staphylococcus aureus 209p were used.

Growth and starvation conditions. All organisms were preincubated in nutrient broth $(3.0 \mathrm{~g}$ meat extract, $10.0 \mathrm{~g}$ peptone and $5.0 \mathrm{~g} \mathrm{NaCl}$ per litre of distilled water, $\mathrm{pH} 7.0$ ) for $12 \mathrm{~h}$ at $35^{\circ} \mathrm{C}$, then cultured at $35^{\circ} \mathrm{C}$ in nutrient broth in $250 \mathrm{ml}$ culture bottles for $24 \mathrm{~h}$ on a reciprocal shaker at 120 r.p.m. The bacteria were harvested by centrifuging at $2500 \mathrm{~g}$; after being washed three times in $0.07 \mathrm{M}$-phosphate buffer $(\mathrm{pH} 7 \cdot 0)$, they were resuspended in the same buffer to a final density of $2 \times 10^{8}$ to $2 \times 10^{9}$ bacteria $\mathrm{ml}^{-1}$ and incubated under the conditions used for growth. We regarded this incubation as starvation (Druilhet \& Sobek, 1975; Boylen \& Mulks, 1977; Thomas \& Batt, 1968).

Counting method. Viability was assessed by plate counts of bacteria diluted in $0.85 \% \mathrm{NaCl}$ solution. The counts were made after incubation at $25^{\circ} \mathrm{C}$ for $48 \mathrm{~h}$. 


\section{RESULTS}

The multiplication rate of bacteria at a given time was assumed to be proportional to the number of cells present at that time, as represented by the equation

$$
\mathrm{d} N / \mathrm{d} t=\kappa N
$$

where $N$ is the number of cells at time $t$, and $\kappa$ is the growth constant. The solution of the equation (1) at the initial condition, $N\left(t_{0}\right)=N_{0}$, is

$$
N=N_{0} \mathrm{e}^{\kappa\left(t-t_{0}\right)}
$$

Equations (1) and (2) represent the exponential growth phase of bacteria when $\kappa>0$ and the stationary phase when $\kappa=0$. Although, according to many textbooks, equations (1) and (2) represent exponential death when $\kappa<0$, in practice the process of bacterial death is not always exponential (Yanagita, 1981). In equation (1) $\kappa$ is constant and independent of $N$. However, the value of $\kappa$ should depend on the value of $N$ at a given time; that is, $\kappa$ is a function of $N, \kappa=\kappa(N)$. So from equation (1), the equation

$$
\mathrm{d} N / \mathrm{d} t=\kappa(N) N
$$

may be obtained.

When $\kappa(N)=\kappa-\lambda N(\kappa>0, \lambda>0)$, the solution of equation (3) at the initial condition, $N\left(t_{0}\right)=N_{0}$, is

$$
N(t)=\frac{\kappa N_{0} \mathrm{e}^{\kappa t}}{\lambda N_{0} \mathrm{e}^{\kappa t}+\left(\kappa-\lambda N_{0}\right) \mathrm{e}^{\kappa t_{0}}}
$$

This is Verhulst-Pearl's logistic equation which fits the growth of bacteria, yeast, Paramecium and Drosophila well (Pielou, 1969).

To describe the death of bacteria in batch culture, we propose that

$$
\kappa(N)=\kappa N^{\alpha}
$$

where $\kappa$ and $\alpha$ are constants. This hypothesis is one of the simplest forms of the function $\kappa(N)$, in which the death rate decreases gradually with $N$ in the case of $\kappa<0$ and $\alpha>0$. From equations (3) and (4), the following equation was obtained:

$$
\mathrm{d} N / \mathrm{d} t=\kappa N^{\alpha} N=\kappa N^{\alpha+1}
$$

This equation could be used to predict the kinetics of death under starvation conditions and in the decline phase. Its solution at the initial condition, $N\left(t_{0}\right)=N_{0}$, is

$$
N(t)=\frac{N_{0}}{\left(1-\alpha \kappa\left(t-t_{0}\right) N_{0}^{\alpha}\right)^{1 / \alpha}}
$$

The constants $\kappa$ and $\alpha$ must be determined in order to apply equations (5) and (6) to the experimental data. From equation (4), putting $t=t_{0}$, the death rate at time $t_{0}$ is

$$
-\kappa\left(N_{0}\right)=-\kappa N_{0}^{\alpha}
$$

This equation is approximately equal to the mean value of the death rates in the short interval between two points before and after time $t_{0}$; as a result,

$$
d=-\kappa N_{0}^{\alpha}
$$

is obtained, where $d$ is the mean value of the death rates. The values of $N$ were determined by plate count, the value of $d$ was determined at two intervals before and after time $t_{0}$, and the value $\kappa$ can be determined if $\alpha$ is known. The value of $\alpha$ is not easily obtained since it seems to vary with the species of bacteria and culture conditions. The most suitable value of $\alpha$ for the experimental data was determined by the method of least-squares.

The values of the parameters for equation (5) under starvation conditions, and the correlation coefficients between logarithms of data and the corresponding calculated values, are shown in Table 1 . The values of $\alpha$ were within a relatively narrow range $(0 \cdot 17-0 \cdot 25)$, and may have an unknown biological meaning. Correlation coefficients were close to 1 , and the theoretical survival curves calculated from equations (5) and (6) fitted the plate count data well (Fig. 1a). 


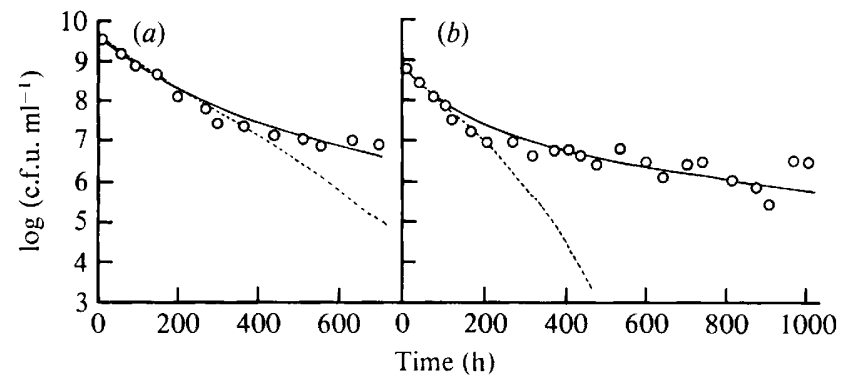

Fig. 1. Survival of $E$. coli starved in phosphate buffer $(a)$, and the decline phase of Staphylococcus aureus in nutrient broth $(b)$. - - Curve calculated from equation (6); --.---, curve calculated from Moats' theory; $\mathrm{O}$, experimental values.

Table 1. Values of the parameters for equation (5) under starvation condition and correlation coefficients $(C)$ between experimental data and theoretical values

\begin{tabular}{lccccc}
\multicolumn{1}{c}{ Bacterium } & $\alpha$ & $d$ & $N_{0}{ }^{*}$ & $\kappa \dagger$ & $C$ \\
Escherichia coli & 0.22 & 0.022 & $2.3 \times 10^{9}$ & $-2.0 \times 10^{-4}$ & 0.990 \\
Serratia marcescens & 0.17 & 0.038 & $6.2 \times 10^{8}$ & $-1.2 \times 10^{-3}$ & 0.998 \\
Salmonella typhimurium & 0.22 & 0.020 & $2.9 \times 10^{9}$ & $-2.1 \times 10^{-4}$ & 0.991 \\
Proteus morganii & 0.25 & 0.071 & $8.1 \times 10^{8}$ & $-4.2 \times 10^{-4}$ & 0.990 \\
& $*$ & \\
& \\
& \\
& \\
& \\
&
\end{tabular}

Table 2. Values of the parameters for equation (5) in the decline phase and correlation coefficients $(C)$ between experimental data and theoretical values

\begin{tabular}{|c|c|c|c|c|c|}
\hline Bacterium & $\alpha$ & $d$ & $N_{0}^{*}$ & $\kappa \dagger$ & $C$ \\
\hline Escherichia coli & $0 \cdot 26$ & $0 \cdot 022$ & $3.5 \times 10^{9}$ & $-7.3 \times 10^{-5}$ & $0 \cdot 970$ \\
\hline Serratia marcescens & 0.22 & 0.061 & $2.0 \times 10^{9}$ & $-5.5 \times 10^{-4}$ & 0.973 \\
\hline Staphylococcus aureus & $0 \cdot 25$ & $0 \cdot 024$ & $6.5 \times 10^{8}$ & $-1.5 \times 10^{-5}$ & 0.956 \\
\hline Staphylococcus aureus $\ddagger$ & $0 \cdot 29$ & 0.053 & $8.0 \times 10^{9}$ & $-7 \cdot 1 \times 10^{-5}$ & 0.971 \\
\hline Salmonella typhimurium $\S$ & $0 \cdot 20$ & $0 \cdot 024$ & $2 \cdot 3 \times 10^{9}$ & $-3 \cdot 2 \times 10^{-4}$ & 0.961 \\
\hline & $\begin{array}{l}\text { Initi } \\
\kappa= \\
\text { Incu } \\
\text { Data }\end{array}$ & $\begin{array}{l}\text { ber } \\
27\end{array}$ & $\begin{array}{l}\text { ria at tim } \\
\text { iles }(1946\end{array}$ & & \\
\hline
\end{tabular}

Fig. $1(b)$ shows the number of surviving cells in the decline phase and the theoretical survival curves calculated from equations (5) and (6). The experimental data fitted the theoretical survival curves, although the fit was better under starvation conditions than during the decline phase. The irregular oscillations with relatively short periods, which were observed in the decline phase of all strains, did not occur under starvation conditions. The values of the parameters for equation (5) in the decline phase and the correlation coefficients are shown in Table 2; the values of $\alpha$ in the decline phase of each strain are similar to those under starvation conditions (Table 1). The correlation coefficients, however, were lower than those under starvation conditions.

\section{DISCUSSION}

The differential equation (5) and its solution (6) quantitatively predicted the survival under starvation conditions during the period $600-1200 \mathrm{~h}$. Moats (1971) proposed the multiple-target theory of thermal death of bacteria and inferred a series of equations on the fraction of survivors. Moats' main equation was

$$
(d / \sigma)^{2}=N\left(\mathrm{e}^{-2 \kappa t}-2 \mathrm{e}^{-\left(\kappa t+\kappa t_{50}\right)}+\mathrm{e}^{-2 \kappa t_{50}}\right) /\left(\mathrm{e}^{-\kappa t}-\mathrm{e}^{-2 \kappa t}\right)
$$


where $\mathrm{d} / \sigma$ is the ratio of deviation from the mean to standard deviation (obtained from a table of the normal probability integral) for the fraction of survivors at time $t ; t_{50}$ is the time at which the fraction of survivors is $0.5 ; N$ is the number of critical sites in each cell and $\kappa$ is the rate constant of inactivation of critical sites. Peled et al. (1977) stated that the kinetics of death under starvation conditions are similar to those of heat-treated cells, and proposed an improved equation. Fig. $1(a)$ indicates the numbers of survivors of $E$. coli under starvation conditions, and shows that the theoretical curve obtained from Moats' equation fits the experimental data from the initiation of starvation well until about $400 \mathrm{~h}$, after which the difference between them increases rapidly. Similarly in Fig. 1(b), which shows the number of survivors of Staphylococus aureus in the decline phase, the difference between the two curves becomes significant after $200 \mathrm{~h}$. The calculated survival curves obtained from equation (6) fit the experimental results better than those obtained from Moats' equation (Fig. 1).

The parameter $\alpha$ may contain some unknown factors, for example, temperature, starvation condition, population heterogenicity (Rahn, 1930), and change of the components of the starvation medium by metabolic products or autolysis of cells (Yanagita, 1981). The value $\alpha$ will be explained by further investigations involving other species of bacteria and conditions of starvation.

We hypothesize that the main factor causing bacterial death in the decline phase is the same as that which causes death under starvation conditions, since the shapes of the survival curves in the two conditions are similar. The oscillations with relatively short periods during the decline phase suggest that a fraction of the population, perhaps comprised of mutants which are resistant to the adverse conditions, grows suddenly during the death process.

\section{REFERENCES}

Boylen, C. W. \& Mulks, M. H. (1977). The survival of coryneform bacteria during periods of prolonged nutrient starvation. Journal of General Microbiology 105, 323-334.

Druilhet, R. E. \& Sobek, J. M. (1975). Starvation survival of Salmonella enteritidis. Journal of Bacteriology 125, 119-124.

MoATs, W. A. (1971). Kinetics of thermal death of bacteria. Journal of Bacteriology 105, 165-171.

Peled, O. F., Salvadoli, A., Peled, U. \& Kidby, D. K. (1977). Death of microbial cells: rate constant calculations. Journal of Bacteriology 129, 1648-1650.

Pielou, E. C. (1969). An Introduction to Mathematical Ecology, 1st edn, chapter 2. New York: John Wiley.

RAHN, O. (1930). The non-logarithmic order of death of some bacteria. Journal of General Physiology 13, 395507.
RAHN, O. (1945). Physical methods of sterilization of microorganisms. Bacteriological Reviews 9, 1-47.

Salle, A. J. (1973). Fundamental Principles of Bacteriology, 7th edn. New York: McGraw-Hill.

Stanier, R., Adelberg, E. \& Ingraham, J. (1976). The Microbial World, 4th edn., chapter 9. Englewood Cliffs, NJ: Prentice-Hall.

Thomas, T. D. \& BátT, R. D. (1968). Survival of Streptococcus lactis in starvation conditions. Journal of General Microbiology 50, 367-382.

Wilson, G. S. \& MiLES, A. A. (1946). Topley and Wilson's Principles of Bacteriology and Immunity, 3rd edn. London: Edward Arnold.

YANAGITA, T. (1981). Biseibutsu kagaku (The Science of Microorganisms), vol. 1, 1st edn, pp. 257-259. Tokyo: Gakkai Shuppan Centre (Japanese Scientific Societies Press). (In Japanese.) 